\title{
Cost-effectiveness of hand hygiene promotion for MRSA blood stream infection in ICU settings
}

\author{
N Luangasanatip ${ }^{1 *}$, M Hongsuwan¹, Y Lubell ${ }^{1}$, D Limmathurotsakul ${ }^{1}$, P Srisamang ${ }^{2}$, NPJ Day ${ }^{1}$, N Graves ${ }^{3}$, \\ BS Cooper ${ }^{1}$
}

From 3rd International Conference on Prevention and Infection Control (ICPIC 2015)

Geneva, Switzerland. 16-19 June 2015

\section{Introduction}

Multimodal interventions are effective in increasing hand hygiene compliance amongst healthcare workers, but it is not known whether such interventions are costeffective outside high-income countries.

\section{Objectives}

To determine whether reductions in Methicillinresistant Staphylococcus aureus bloodstream infections (MRSA-BSI) alone would make hand hygiene interventions cost-effective in intensive care units (ICUs) in a middle-income country using a model-based framework.

\section{Methods}

Transmission dynamic and decision analytic models were combined to determine the expected impact of hand hygiene interventions on MRSA-BSI incidence and evaluate their cost-effectiveness. Epidemiological and economic parameters were derived using data from a tertiary hospital in North-east Thailand. Sensitivity analyses were performed with different values for MRSA transmissibility and colonization prevalence on admission.

\section{Results}

Interventions increasing hand hygiene compliance from a $10 \%$ baseline to $\geq 20 \%$ are likely to be cost-effective solely through reduced MRSA-BSI. Increasing compliance from $10 \%$ to $40 \%$ was estimated to cost \$US 89.1 per bed-year with 4.07 QALYs gained per 10,000 beddays in the paediatric ICU (PICU) and \$US 63.3 per bed-year with 4.03 QALYs gained per 10,000 bed-days in the adult ICU. If baseline compliance is not greater than $20 \%$, the intervention is always cost-effective even with only a $10 \%$ compliance improvement.

\section{Conclusion}

Effective multimodal hand hygiene interventions are likely to be cost-effective in ICU settings in typical middleincome countries where baseline compliance is low due to preventing MRSA-BSI alone. Where compliance is higher, the cost-effectiveness of interventions to improve it further will depend on the impact on HAIs other than MRSA-BSI.

\section{Disclosure of interest}

None declared.

\section{Authors' details}

${ }^{1}$ Mahidol-Oxford Research Unit, Bangkok, Thailand. ${ }^{2}$ Pediatrics, Sappasithiprasong Hospital, Ubon Ratchatani, Thailand. ${ }^{3}$ School of Public Health, Queensland University of Technology, Brisbane, Australia.

Published: 16 June 2015

doi:10.1186/2047-2994-4-S1-050

Cite this article as: Luangasanatip et al: Cost-effectiveness of hand hygiene promotion for MRSA blood stream infection in ICU settings. Antimicrobial Resistance and Infection Control 2015 4(Suppl 1):O50.

${ }^{1}$ Mahidol-Oxford Research Unit, Bangkok, Thailand

Full list of author information is available at the end of the article

(c) 2015 Luangasanatip et al; licensee BioMed Central Ltd. This is an Open Access article distributed under the terms of the Creative Commons Attribution License (http://creativecommons.org/licenses/by/4.0), which permits unrestricted use, distribution, and reproduction in any medium, provided the original work is properly cited. The Creative Commons Public Domain Dedication waiver (http://creativecommons.org/publicdomain/zero/1.0/) applies to the data made available in this article, unless otherwise stated. 